\title{
Archivo oral de la Comisión Provincial por la Memoria. Memorias encontradas: el archivo y el testigo
}

\begin{abstract}
The oral archive of the Provincial Commission for the Memory (CPM) in Buenos Aires. Encountered memories: the archive and the witness
\end{abstract}

Julieta Sahade

Programa de gestión y preservación de archivos de la Comisión Provincial por la Memoria, Argentina archivo@comisionporlamemoria.org

Ingrid Jaschek

Programa de gestión y preservación de archivos de la Comisión Provincial por la Memoria, Argentina archivo@comisionporlamemoria.org

\begin{abstract}
RESUMEN:
Esta conferencia formó parte del encuentro "Archivos Sonoros y cultura popular" realizado el 17 de septiembre de 2019 en el marco del Coloquio sobre Memorias Populares organizado por Doctorado en Historia y la Maestría en Historia y Memoria de la FaHCE junto a la presencia del historiador italiano Alessandro Portelli. En dicha conferencia, las autoras presentaron el archivo oral "Memorias encontradas" de la Comisión por la Memoria (CPM). Por un lado, relataron la historia de la producción y recolección de entrevistas surgidas a partir de los distintos trabajos de la CPM y, por el otro, reflexionaron sobre algunas particularidades de la serie "El archivo y el testigo": el contexto de producción, el diálogo entre el relato oficial/policial y la voz de las y los testigos, los distintos modos de narrar, de contar.
\end{abstract}

Palabras Clave: Archivo oral, Conintes, Militancia política, Memoria.

\section{Abstract:}

This lecture was part of the "Sonorous archives and popular culture" meeting which took place on September 17th, 2019 during the Colloquium on Popular Memories organized by the postgraduate careers at FaHCE (UNLP), Doctorate in History and Master in History and Memory, together with the Italian historian, Alessandro Portelli. During the lecture, the keynote speakers, Ingrid Jaschek and Julieta Sahade, presented the oral archive "Encountered Memories" from the Provincial Commission for the Memory (CPM) institution in Buenos Aires. In doing so, they described, on one hand, the history of the production and collection of a group of interviews developed by the different projects at the CPM and, on the other hand, they reflected about some particularities of the series "The archive and the witness": the context of production, the dialogue between the official / police reports and the voice of the witnesses, the different ways of narrating and telling.

KeYwORDS: Oral Archive, Conintes, Political activism, Memory.

Ingrid Jaschek: Buenos días a todos, les agradecemos profundamente la invitación. Muchos ya conocen la experiencia de la Comisión pero otros no, así que voy a hacer un breve repaso para aquellos que no la conocen. Nosotras trabajamos en la Comisión Provincial por la Memoria (CPM) de la Provincia de Buenos Aires que este año cumple veinte años. Arrancó allá por el año 1999 como un organismo público orientado a la defensa de los derechos humanos y fue generando múltiples líneas de trabajo en la Provincia de Buenos Aires. La CPM nació muy ligada a pensar el pasado reciente, el autoritarismo y la última dictadura militar, pero casi inmediatamente empezó a trabajar en la defensa de los derechos humanos en el presente, entendiendo que es ahí donde la memoria cobra sentido. En esas múltiples líneas de acción desarrollamos el Comité contra la Tortura que trabaja con personas privadas de libertad, en cárceles o en otros lugares de encierro como los neuropsiquiátricos. Impulsamos el programa Jóvenes y Memoria que convoca a estudiantes secundarios y de 
organizaciones desde el año 2002 para que investiguen sobre historias locales, generando espacios de escucha y de intercambio generacional. Nosotras específicamente trabajamos en el Programa Gestión y Preservación de Archivos, que gestiona desde el año 2001 el archivo de lo que fue la Dirección de Inteligencia de la Policía de la Provincia de Buenos Aires, conocido como el archivo de la DIPPBA.

A partir de esos espacios de trabajo se fue generando un archivo oral, que en un principio no visualizábamos como tal: eran entrevistas para producciones audiovisuales específicas con quienes se acercaban a los programas de trabajo, o a los que nosotros íbamos a buscar como, por ejemplo, las entrevistas a gente privada de su libertad. Una digresión en relación con los registros en las cárceles: en un principio entrábamos con cámaras, luego hubo una prohibición por parte del gobierno de Felipe Solá y sólo se registraba en audio, unos años después volvimos a grabar con cámaras.

Retomando la génesis del archivo oral, empezó a acumularse una gran cantidad de registros audiovisuales relacionados con víctimas del pasado y del presente, o con los nuevos actores que empezaban a surgir en el contexto político de esos años -1999, 2000, 2001, 2002- donde eran muy incipientes los estudios de memoria y todavía estaban vigentes las leyes de impunidad. Como decía Alessandro Portelli: no es que no había voces, sino que no había lugares de escucha. Entonces la CPM de alguna manera fue un vehículo para poner esa escucha al servicio de distintos actores sociales.

Ese registro -que como decía en un principio fue caótico y que estaba pensado para algunas producciones específicas- en el año 2008 decidimos sistematizarlo y hacer un archivo oral. Una cosa para tener en cuenta es que además de una gran diversidad de voces, había también una enorme diversidad de soportes: desde VHS hasta UMATIC, BETACAM, Mini DV, DVCAM, etc. La idea de organizar el archivo buscó, por un lado, que esté accesible y disponible a la consulta pública -y esto implicó la digitalización- y por el otro, la organización de los materiales (esto es, la contextualización de cada una de esas producciones).

Julieta Sahade: También en relación con la preservación porque, como decía Ingrid cuando mencionó el ejemplo de Jóvenes y Memoria, el objetivo era también promover la preservación, la puesta en conocimiento, la identificación de las producciones que se generaban en las propias escuelas de la ciudad de La Plata, de Mar del Plata, de Bahía Blanca y de los distintos pueblos de la provincia. El Programa también nos permitía pensar eso en su dimensión más valiosa, diversa, singular, de promover la preservación y de poner en común los propios trabajos. Es decir, si un investigador o investigadora quisiera estudiar sobre la militancia estudiantil, obrera, en Pergamino, podría utilizar también lo investigado por las propias escuelas que hacen investigaciones locales muy ricas.

Ingrid Jaschek: Sí, además, la característica principal del Programa Jóvenes y Memoria es que quienes hacen las entrevistas son los jóvenes y de esa manera se produce un diálogo muy diferente al que podríamos plantear desde nuestra institución. Y además de organizar el archivo, nos propusimos hacer series específicas ya para un archivo oral; es el caso que después vamos a presentar con Julieta, que tiene que ver con ex presos Conintes, es decir, ya pensando en determinados grupos de entrevistas alrededor de un tema, o ligado al archivo de la DIPPBA. Le pusimos el nombre de "Memorias encontradas" porque nos parecía que tenían que ver con ese doble sentido de memorias que se van encontrando: se van encontrando porque las encontramos, se van encontrando entre ellas y también porque concebimos a la memoria como una diversidad, como una pluralidad, como una tensión, como una disputa de sentidos. También ese "encontradas" tiene que ver con algunas que están "enfrentadas”; es nuestra forma de concebir la memoria.

El problema que nos planteamos fue: si nosotras no íbamos a hacer una investigación específica sino una serie de entrevistas para un archivo oral, ¿qué tipo de entrevistas haríamos? ¿Quién sería el interlocutor?

El interlocutor es la CPM, generalmente mediado por un vínculo que creamos quienes actuamos en el territorio con las personas, quienes atendemos a las víctimas que vienen a buscar sus documentos al archivo. Entonces, fue empezar a poner en claro esos lugares desde donde íbamos a construir este archivo oral y especificarlo, decirlo, pensar qué tipos de entrevistas -ahora lo vamos a ver más específicamente cuando pensemos los ex presos Conintes-: historias de vida, entrevistas puntuales a partir de un tema. Nos parecía 
que no había que cerrarse a un tipo de entrevistado específico y sí había que pensar qué validez podían tener esas memorias para el futuro, ¿no? Porque el investigador que hace ahora su investigación prefiere hacer sus propias entrevistas, pero hay un montón de gente que se va a ir muriendo, que no va a estar y que es muy importante que queden registradas esas voces.

Julieta Sahade: Y nos parece muy importante entender estos contextos, por lo cual tratamos de ser prolijas en explicarlos. Como Ingrid decía, no es lo mismo esas entrevistas que fueron generadas y producidas por adolescentes que las que fueron generadas en este marco. En consecuencia, explicar cada contexto de producción creo que nos ayuda un poco a pensar distintos usos. Otro de los ejes que tiene el archivo es algo que denominamos "El archivo y el testigo". A partir de este eje se hicieron distintas producciones que tenían que ver con los distintos usuarios del archivo. Desde que se abrió en el año 2003, se han respondido más de trece mil consultas personales y más de tres mil de investigadoras e investigadores, además de los requerimientos para las causas judiciales de lesa humanidad. Y ese acercamiento que se genera al archivo y que se generó desde el inicio es muy particular, no es un trámite burocrático; recién ahora existen algunas instancias de la solicitud vía internet. Pero en general no es un trámite sino que es un encuentro, ese encuentro tiene características muy particulares, algunas son muy dolorosas, algunas están repletas de expectativas, otras son de mucho hermetismo, pero siempre son importantes, momentos históricos, de contar y escuchar. Y distintas narraciones: desde pensar en grandes referentes de la militancia política platense a personas que cuentan y se reconocen como víctimas por primera vez en el 2017 y que son de Berisso, Ensenada, del Conurbano. La diversidad es enorme, y esa diversidad genera distintos tipos de acercamientos, y una necesidad de contar que nosotros la tradujimos como una necesidad de registrar ese encuentro.

El archivo tiene características muy particulares. Es un archivo de inteligencia político-ideológica donde está el relato oficial, escrito y de la policía. Entonces, el registrar ese momento implica además poner en discusión lo que dice el papel. Abren un diálogo entre el relato individual, personal y un relato oficial escrito. Ese momento histórico de registro es lo que nosotros denominamos "El archivo y el testigo", que ha tenido distintas formas y que las va a seguir teniendo porque vamos a continuar en esa búsqueda de pensar ese diálogo. Vamos a mostrar algunos ejemplos de esta serie particular de Conintes y después unos cortos que hicimos.

Ingrid Jaschek: Los cortos a los que refiere Julieta se pensaron como difusión del archivo de la DIPPBA, para que la gente se acerque a consultarlo. Se coprodujeron con el canal educativo Encuentro y se emitieron por esa señal. Eran ocho entrevistas a personas que habían consultado el archivo, y cada entrevista se editó en un corto de cinco minutos. Mantenían la diversidad tanto de género como de edades; algunas historias estaban referidas a sus padres, otras a ellos mismos. Algunos tenían reconocimiento público como Adolfo Pérez Esquivel o Nora Cortiñas, otros no.

Les vamos a presentar un fragmento del crudo de las entrevistas que hicimos a Adolfo Bergerot y a Marta Jáuregui. Hay que tener en cuenta que estaban pensadas para difusión -tenía una puesta en escena- y no como una entrevista como las que habitualmente hacemos tratando de que desaparezca todo el artilugio tecnológico. Para el entrevistado eran puestas en escena dentro del archivo que también activaba una memoria muy particular. Comenzamos con un fragmento de la entrevista a Adolfo Bergerot, militante de los años 70 detenido en el año 76.

"Firma". Fragmento de entrevista a Adolfo Bergerot para cortometraje "El archivo y el testigo". Archivo Oral "Memorias encontradas", CPM: https://youtu.be/z36ryLX74as

Ingrid Jaschek: Lo interesante es ver cómo el documento escrito, esa memoria policial, oficial y judicial en este caso (porque en realidad es un testimonio judicial) va activando su propio recuerdo y se va poniendo en discusión. También es interesante cómo él va recordando esas estrategias de supervivencia, ¿no?

Julieta Sahade: En esto de las diversidades para seleccionar, hay determinadas personas que se acercan y nunca han contado su experiencia. Pero en el caso de Adolfo, él sí había dado testimonio, entonces tenía cierta posibilidad de reflexionar, se permite distancias, una forma de narrar muy distinta a lo que después vamos a ver. 
Ingrid Jaschek: El otro corto es de Marta Jáuregui. Brevemente: Marta Jáuregui, es una dirigente gremial de La Plata, y su papá Juan Martín Jáuregui fue asesinado en el año 75, el 19 de octubre, resistiendo en su casa en el marco de un operativo muy grande. Ella también fue a buscar los documentos al archivo.

Cortometraje "El archivo y el testigo" - Marta Jauregui: https://www.youtube.com/watch?v=prS-_O S4f_g

Ingrid Jaschek: Es bastante evidente todo lo que venimos diciendo: esa forma de relatar, un testimonio en carne viva. Ella rescata del diario, a pesar de que tenía un montón de cosas más relacionadas con la intimidad (cosas más de la familia), lo que tiene que ver también con su propia identidad de militante gremial en la ciudad de La Plata. Acá no se ve pero en otros tramos de la entrevista ella está contestando todo el tiempo a los documentos periodísticos, a lo que decía El Día -el diario de La Plata-. "Era mentira que esta era casa de extremistas, era mi casa"; a lo largo de todo el testimonio pone en tensión los documentos y a la vez recibe ese diario increíble, escrito por su padre hasta doce horas antes de que lo maten (el parte de muerte dice que murió, que lo terminan de matar el 19 de octubre y él escribe hasta el 18 a la noche, algo muy impactante). Ahora vemos el corto de Adolfo Bergerot como fue publicado:

Cortometraje "El archivo y el testigo" - Adolfo Bergerot:https://www.youtube.com/watch?v=5pVaC $\mathrm{GdDyGw}$

Ingrid Jaschek: Así fue finalmente cómo se dio el encuentro y ese diálogo entre los documentos, la memoria policial, judicial, oficial y sus propios recuerdos. Él dice que no sabía que el Estado tenía un registro de que esto había pasado. Eso es un poco el sentido de estos encuentros con los documentos.

Julieta Sahade: Sí, y además que estos cortos fueron pensados para difusión, para difundir al archivo, también nos permiten entender ese fondo, digo pensando en la cantidad de investigadores, investigadoras que consultan el archivo. Nos ayuda a pensarlo a nosotras que estamos ahí gestionando pero también para otras consultas.

Cuando empezamos a pensar el archivo oral y una serie específica, la primera que encaramos de manera más cerrada fue aquella con los presos Conintes, fundamentalmente con militantes de la resistencia peronista. Hubo algunos que no, pero mayoritariamente pertenecieron a la resistencia peronista, y en el marco de una ley reparatoria se acercaron al archivo. Venían colectivamente y empezaron a organizarse, bien peronistas, para hacer consultas fundamentalmente buscando algún documento que les sirviera para presentar y para tramitar la ley. Eran escenas muy dantescas (risas), muy pintorescas y nos pareció que era una serie ideal para empezar a hacer entrevistas a ese colectivo y que pudieran dar cuenta de la documentación, pero sobre todo del vínculo con la institución, con el archivo. Pensamos mucho esa serie, su diversidad y en las formas de encarar esas entrevistas.

"Presentaciones". Fragmentos de entrevistas a ex presos del Plan Conintes. Archivo Oral "Memorias encontradas", CPM, Serie Presos Conintes:https://youtu.be/mgeP_7qE7ck

Julieta Sahade: Esa selección diversa tuvo algunas características y es que Manuel, que era el que cerraba el fragmento audiovisual, gestionaba un poco esa organización y cuando le contamos la idea, no quería que lo entrevistáramos a él, sino que ponía referentes más académicos porque sentía que su experiencia no tenía valor. En esas diversidades están los que tienen sello más académico y también están los que no lo tienen. La serie "Conintes" tiene dos entrevistados que no son peronistas, sino que son del Partido Comunista, uno aparece en las presentaciones. El entrevistado que aparece sentado junto a su esposa -que la sentó al lado aunque no habló- lo elegimos para mostrar el contexto, pensamos mucho los contextos. Las hicimos -salvo la de Manuel- en las casas, y esas casas tenían lo que tenía cada casa: oscuridades, por ejemplo. La decisión era un poco esa, mostrar esos condimentos que hacían a esas diversidades y que apostamos a eso, ¿no?

Ingrid Jaschek: Pensando en lo de Manuel Gallardo, es interesante ver cómo también el contexto fue cambiando desde esa primera entrevista que hicimos. En realidad él participó del robo del sable de San Martín y no es un acontecimiento que a él particularmente le guste contar o narrar. 
Julieta Sahade: Al menos no en ese momento, después sí se fue reconciliando y ese episodio lo fue contando distinto. Cuando inicialmente se acercaron al archivo recién empezaban a ser reconocidos por el Estado; y había una disputa implícita con el lugar de reconocimiento social que sí tenía la militancia de los años 70. En ese momento había una necesidad de transmitir un legado de la historia, por ello la decisión de dar testimonio, de que quede registro y de contar lo que pasó porque se sentían olvidados y olvidadas dentro de un relato histórico. Pero eso fue cambiando, no es el mismo Manuel después de haber realizado el documental ("El sable” https://youtu.be/eZ84FSL4c7k de Nahuel Machesich) sobre el robo del sable de San Martín; se ha reconciliado un poco con eso y ha recibido otras miradas sociales que lo ubicaron en otro lugar.

"Evita". Fragmento de entrevista a Lala Marín. Archivo Oral "Memorias encontradas", CPM, Serie Presos Conintes:https://youtu.be/CaratP2byAI

Julieta Sahade: Pusimos este fragmento primero porque es muy simpático, pero después porque hay mucha diversidad en la forma de relatar. En las entrevistas a los ex presos Conintes muchos se animan a lo anecdótico y evidencian cómo lo anecdótico ejemplifica y refiere a procesos históricos. Hay otros testimonios que son más ásperos y distantes que costó mucho sacar lo anecdótico. Por ejemplo, Manuel que tenía una intención más de contar la historia con mayúsculas, no lo personal. Por otro lado, nos servía como disparador para contar todas las discusiones que tuvimos en relación con el armado y el guión de las entrevistas. Por ejemplo, nos planteamos como historias de vida, pero discutimos mucho acerca de hasta dónde mencionar los acontecimientos históricos para que el entrevistado opinara sobre eso. Después nos dimos cuenta de que no, de que los silencios también decían algo y si no aparecía, por algo era. En una de las entrevistas a una mujer, no aparecía la palabra Evita por ningún lugar y ahí sí decidimos preguntarlo porque esa ausencia necesitábamos verbalizarla y estuvo bueno porque mencionó una cuestión familiar personal con Evita y que por eso la había borrado de su memoria.

Ingrid Jaschek: Volvemos a Lala Marín que es un poco como uno se inscribe en la Historia con mayúscula.

"Lealtad". Fragmento de entrevista a Lala Marín. Archivo Oral "Memorias encontradas", CPM, Serie Presos Conintes:https://youtu.be/NugZj3JqpZ0

Julieta Sahade: Aquí aparece lo mismo en relación a lo anecdótico y también a la cuestión de la historia, del legado que en ella está y que en Manuel también. Para cerrar quisiéramos decir que muchas de estas entrevistas tienen instancias que pueden ocurrir producto del vínculo que se genera en el encuentro y de la referencialidad con el archivo. Me refiero a la calidez y a lo entrañable de esos encuentros, no es la única forma, pero parte de las entrevistas se entienden por ese vínculo tierno y de mucha referencialidad que se genera con la CPM.

Ingrid Jaschek: Con las personas y con la institución, también. 